\title{
Utilization and Associated Factors of Modern Contraceptives During Extended Postpartum Period among Women Who Gave Birth in the Last 12 Months in Gondar Town, Northwest Ethiopia
}

\author{
Marta Berta ${ }^{1}$, Amsalu Feleke ${ }^{2}$, Tatek Abate ${ }^{2}$, Temesgen Worku', Teklay \\ Gebrecherkos $^{3 *}$
}

OPEN ACCESS

Citation: Marta Berta, Amsalu Feleke, Tatek Abate, Temesgen Worku, Teklay Gebrecherkos. Utilization and Associated Factors of Modern Contraceptives During Extended Postpartum Period among Women Who Gave Birth in the Last 12 Months in Gondar Town, Northwest Ethiopia. Ethiop J Sci. 2018;28(2):207. doi:http://dx.doi.org/10.4314/ejhs.v28i2.12 Received: October 25, 2017 Accepted: November 2, 2017

Published: March 1, 2018

Copyright: (C) 2018 Marta Berta., et al This is an open access article distributed under the terms of the Creative Commons Attribution License, which permits unrestricted use, distribution, and reproduction in any medium, provided the original author and source are credited. Funding: University of Gondar

Competing Interests: The authors declare that this manuscript was approved by all authors in its form and that no competing interest exists.

Affiliation and Correspondence:

${ }^{1}$ Department of Midwifery, College of Medicine and Health

Sciences, University of Gondar, Gondar, Ethiopia

${ }^{2}$ Department of Health Management and Health Economics,

Institute of Public Health, University of Gondar, Gondar,

Ethiopia

${ }^{3}$ Department of Medical

Microbiology, CMHS, UOG,

Ethiopia

*Email: estiftg17@gmail.com

\begin{abstract}
BACKGROUND: The postpartum period is a critical period for addressing widespread unmet needs in family planning and for reducing the risks of closely spaced pregnancies. However, many women do not realize that they are at risk for pregnancy during this period. Therefore, the aim of this study was to assess utilization and associated factors of modern contraceptives during extended postpartum period.

METHODS: Institutional based cross-sectional study was conducted from March to April, 2015 in six health institutions among women who gave birth in the last 12 months prior to the study period in Gondar Town, Northwest Ethiopia. A systematic random sampling technique was used to select the study participants. Data were analyzed using SPSS version 20. Bivariate and multivariate logistic regression models were fitted to identify the determinants of postpartum modern contraceptive use. Adjusted odds ratios with 95\% confidence intervals were calculated, and p-values $<0.05$ were considered to indicate statistical significance.

RESULT: Of the total 404 participants, $45.8 \%$ mothers used modern contraceptives during postpartum period. Injectable contraceptive was the most frequently used method. Menstruating [AOR $=3.84,95 \%$ CI: (2.33, 6.35)], resumption of sex $[A O R=3.17,95 \%$ CI: $(1.80,5.58)]$, $37-51$ weeks of postpartum period [AOR $=2.48,95 \%$ CI: $(1.11,5.55)]$, husband approval of contraceptive [AOR $=2.10,95 \%$ CI: $(1.16,3.82)]$ and current knowledge on FP $[A O R=5.01,95 \%$ CI: $(2.23,11.24)]$ were factors affecting contraceptive use in postpartum period.

CONCLUSION: Utilization of modern contraceptive during the postpartum period was significantly decreased placing women at risk for a pregnancy in the extended postpartum period. Menstruating, resumption of sex, variation on postpartum period and husband approval of contraceptive were factors associated with contraceptive use. Strengthening FP counseling service at the ANC clinic and postnatal care would improve contraceptive use during the postpartum period.
\end{abstract}

KEYWORDS: Post partum, Modern contraceptives, Utilization, Northwest Ethiopia 


\section{INTRODUCTION}

Postpartum family planning is defined as the prevention of unintended pregnancy and closely spaced pregnancies through the first 12 months after childbirth (1). It is usually given less emphasis regarding family planning (FP) by policy makers, service providers and users. It is also a period when women usually have a high unmet need for FP (2) .

The World Health Organization (WHO) describes the postnatal period as the most critical and yet the most neglected phase in the lives of mothers and babies; most deaths occur during the postnatal period (3). Worldwide, there are 265 million unwanted pregnancies, 110 million unnecessary abortions, 590,000 avoidable maternal deaths and 8 million preventable infant deaths (4). Sub-Saharan Africa has one of the highest fertility rates in the world, which is further promoted by the low utilization of modern contraceptive methods. Yet, many communities claim to have traditional methods of family planning that pre-date the introduction of modern contraceptives, implying that contraception is a culturally acceptable norm (5).

According to the WHO technical consultation committee for better maternal and child health outcomes, an interval of at least 2-year following a live birth is recommended before becoming pregnant again (6). Pregnancies occurring within a year of the mother's previous birth are highly at risk for the health of both the mother and the child than those occurring later (7).

For this reason, the mother can develop different complications like spontaneous abortion, postpartum bleeding and anemia. On the other hand the new born could be born with preterm and low birth weight and the index child might receive inadequate care and support which, thereafter, could lead to vulnerabilities to disease and malnutrition

In Ethiopia, evidence has been shown that nearly half $(47 \%)$ of all pregnancies occur within a short birth interval of less than two years after the preceding birth (10). The country is characterized by a very high fertility, low life expectancy, high maternal and child mortality, poor nutritional status, high infant mortality and low per capital income (11-13).

The postpartum period presents a rising risk of unwanted conception and often-frustrated desire for contraceptive protection. From 7-9 months after birth, most women become exposed to pregnancy but do not want to become pregnant again so soon, yet still do not obtain contraceptive protection. Such women have experienced a return of menses, are not abstaining from intercourse, and are unprotected from conception $(14,15)$.

Maternal health remains a major global concern since pregnancy and childbirth are the leading causes of death, disease and disability among women 15-45 years of age. This concern is also well acknowledged in the fifth Millennium Development Goal (MDG-5) that aims to reduce maternal deaths and provide universal access to sexual and reproductive health services by 2015 . Evidence shows that encouraging early antenatal care visits, institutional deliveries, postnatal care and contraceptive adoption to promote longer birth intervals are key elements in improving safe motherhood $(16,17)$.

Family planning promotion is unique among medical interventions in the breadth of its potential benefits: reduction of poverty, and maternal and child mortality; empowerment of women by lightening the burden of excessive childbearing; and enhancement of environmental sustainability by stabilizing the population of the planet (18).

In Ethiopia, breast feeding is universal but exclusive/optimal breast feeding practices are poor in which only half (52\%) of children under six months in Ethiopia are being exclusively breastfed (19). So, by this situation, the use of lactational amenorrhea cannot be effectively and reliably used as a method of contraception.

Therefore, this research sought to investigate the practice and factors associated with postpartum modern contraception, particularly in the extended postpartum period. This will be very important for designing appropriate family

DOI: http://dx.doi.org/10.4314/ejhs.v28i2.12 
planning interventional strategies as well as to have a big contribution for reduction of mother and infant mortality and morbidity rates in the country at large.

\section{METHODS}

Study design, area and study participants: An institutional based cross-sectional study was conducted in six public health institutions (Gondar University Referral Hospital, Policlinic, Azezo Health center, Maraki Health Center, Woleka Health Center and Theda Health Center) of Gondar town, Northwest Ethiopia from March to April, 2015. Gondar town is located in North Gondar Zone of the Amhara Regional State, 750 $\mathrm{km}$ Northwest to Addis Ababa. According to the 2007 Ethiopian census report, Gondar town has a projected total population of 206,987 $(98,085$ male and 108,902 female), and about 58,863 women in the reproductive age group. The health care system of the town is presented by nine governmental health institutions, one private hospital and six higher private clinics. Women who gave birth within the last 12 months and visited immunization clinic at governmental health institutions during the study period were included.

Sample size and Sampling technique: The sample size was determined by using the single population proportion formula with the following assumptions: The proportion of women using contraceptive in postpartum period was taken from a previous study $48.8 \%$ (20), 95\% confidence level and 5\% margin of error. Considering a 5\% non-response rate, the final sample size was 404. A systematic random sampling technique was used by considering the six public health institutions ANC (immunization) clinics on average gave FP service for 17 postpartum women per day. Since the sample collection period for this study was for two months, the total amount of postpartum women that came to the health institutions for service was 1050. To determine $\mathrm{K}$, the following formula was used, $\mathrm{K}=\mathrm{N} / \mathrm{n}=1050 / 404=2.5$, so every 2 postpartum women that came to the ANC clinic from March to April was included in the sample until the required sample was achieved.
Data collection procedure: Data were collected by a structured and pretested questionnaire via face-to-face interview at the health institutions. The questionnaire and consent documents were first developed in English, then translated into Amharic, and finally retranslated into English by another translator to check the consistency. Training was given for data collectors and supervisors before the actual data collection.

\section{Operational definitions}

Contraceptive use in the extended postpartum: Initiation and use of modern contraception from six week to 12 months of postpartum period

Modern contraceptive: A product or medical procedure that interferes with reproduction from acts of sexual intercourse

Data quality control: Data quality was controlled through the provision of training to the data collectors and supervisors about the overall data collection procedures and the techniques of interviewing. A pre-test was done using $5 \%$ of the sample questionnaire before the actual data collection in the adjacent town (Debarik Hospital) to ensure the clarity of the questionnaire and necessary corrections were made based on the pre-test. Moreover, it was assumed to check the wording and to confirm the logical sequence of the questions with a population of postpartum women presumed to have similar sociodemographic characteristics to the population of the study area.

The collected data were checked for completeness, consistency, accuracy and clarity by the co-authors and the principal investigator on a daily basis.

Data processing and analysis: Data were checked for completeness and entered into EPI INFO version 3.5.3 statistical software and then exported to SPSS version 20 for further analysis. Frequencies and cross tabulations were used to summarize descriptive statistics. Binary and Multi variable logistic regression was used to identify variables associated with contraceptive utilization and to control confounders. The strength of association was interpreted using the adjusted odds ratio and $95 \%$ CI. The criterion for statistical significance was set at a $\mathrm{p}$ value of 0.05 . 
Ethical considerations: Ethical clearance was obtained from the Institution Review Board of the Institute of Public Health, the University of Gondar. Formal letters of cooperation were written to the different health institutions in Gondar Town and Gondar Woreda Health Offices. Verbal consent was obtained from each study participants. Moreover, the participants were assured that the information would be kept confidential.

\section{RESULTS}

Socio-demographic characteristics of study participants: A total of 404 women who were in the first year after delivery were interviewed. The majority, 359/404 (88.9\%), of the respondents were in the age group of 26-35 and Amhara in ethnicity. More than three-fourth of the participants, 385/404 (95.3\%), were married and 285/404 (70.5\%) were housewives. The majority, $341 / 404(84.4 \%)$, of the participants were Orthodox Christians, and 175/404 (43.3\%) of them were reached high school and above (Table 1).

Obstetric and gynecologic characteristics: The average number of pregnancies per woman was 2 with a minimum of 1 and a maximum of 10 pregnancies while average number of currently alive children was 2 per woman. Three hundred seventy $(91.6 \%)$ of the study participants had ANC visit at least once for their recent pregnancy, $323 / 404(80 \%)$ delivered in health institutions and $327 / 404(86.4 \%)$ had contact with a health professional during the postpartum period.

Concerning the reproductive intention of the study subjects, $169 / 404$ (41.8\%) of the postpartum women who wanted to space next pregnancy, $136 / 404(33.7 \%)$ who wanted to limit their family size and $26 / 404(6.9 \%)$ of the postpartum women who wanted to would have a child soon. Limiting and spacing needed differ by the number of alive children that a woman had. Spacing need was the highest among mothers who had 1-2 alive children 172/404 (57\%) and limiting need was the highest among those who havd 5-10 alive children 19/404 (95\%).

Table 1: Percentage distribution of the study population by socio-demographic characteristics, Gondar town, Northwest Ethiopia, April 2015.

\begin{tabular}{|c|c|c|}
\hline Variable & Number & $\%$ \\
\hline \multicolumn{3}{|l|}{ Maternal age } \\
\hline $20-25$ & 23 & 5.7 \\
\hline $26-35$ & 359 & 88.9 \\
\hline$\geq 35$ & 22 & 5.4 \\
\hline \multicolumn{3}{|l|}{ Marital status } \\
\hline Married & 385 & 95.3 \\
\hline Single & 14 & 3.5 \\
\hline Other (Widowed, Separated, & 5 & 1.2 \\
\hline \multicolumn{3}{|c|}{ Divorced) } \\
\hline \multicolumn{3}{|l|}{ Religion } \\
\hline Orthodox & 341 & 84.4 \\
\hline Muslim & 53 & 13.1 \\
\hline $\begin{array}{l}\text { Others } \\
\text { (protestant and catholic) }\end{array}$ & 10 & 2.5 \\
\hline \multicolumn{3}{|l|}{ Ethnicity } \\
\hline Amhara & 380 & 94.1 \\
\hline Tigre & 20 & 5.2 \\
\hline Others ( Oromo and gurage) & 4 & 0.7 \\
\hline \multicolumn{3}{|l|}{ Education } \\
\hline Illiterate & 95 & 23.2 \\
\hline Primary school & 134 & 33.5 \\
\hline High school and above & 175 & 43.3 \\
\hline \multicolumn{3}{|l|}{ Occupation } \\
\hline House wife & 285 & 70.5 \\
\hline Employee & 58 & 14.4 \\
\hline Student & 24 & 5.9 \\
\hline Merchant & 17 & 4.2 \\
\hline Daily labourer & 11 & 2.7 \\
\hline \multicolumn{3}{|l|}{ Monthly income } \\
\hline $100-700$ & 100 & 24.8 \\
\hline $700-2000$ & 242 & 59.9 \\
\hline$\geq 2000$ & 62 & 15.3 \\
\hline
\end{tabular}

DOI: http://dx.doi.org/10.4314/ejhs.v28i2.12 
More than half (65.1\%) of the study participants had already started sexual intercourse after giving birth and less than half $(40.3 \%)$ of the study participants had already resumed menses after birth, and the rest were still amenorrheaic.

Utilization of contraceptive method during the extended postpartum period: The prevalence of modern contraceptive use among women in the extended postpartum period was found to be 185/404 (45.8\%) (95\% CI: 41.3, 51). The most commonly used contraceptive method was injectables 103/185 (55.6\%) followed by pills $41 / 185(22.2 \%)$ and lactational amenorrhea method users $12 / 185(6.5 \%)$. The majority of women who wanted to space or limit were using short term hormonal family planning methods. From these, 26/185 (14.1\%) and 56/185 (30.3\%) who wanted to space used pills and injectables, respectively.

Out of those who were menstruating and initiated sexual activity, $114 / 185(61.6 \%)$ and $155 / 185(83.7 \%)$ of them used contraceptive method, respectively. The major reasons for not using contraceptives at the extended postpartum period for $67 / 185(36.23 \%)$ of the participants was feeling of insusceptible of pregnancy due to amenorrhea after birth. Others 31/185(16.75\%) reported that feeling of insusceptible of pregnancy were due to breastfeeding (Table 2).

Table 2: Reproductive intention and types of family planning methods used by women in the extended postpartum period, Gondar town, April 2015 ( $\mathrm{n}=185)$.

\begin{tabular}{llllll}
\hline \hline \multirow{2}{*}{ Reproductive intention } & \multicolumn{2}{l}{ Currently used family planning methods } & \\
& pills & injectable & others & All methods & No method \\
\hline Want to space & $26(25.7)$ & $56(55.4)$ & $19(18.8)$ & $101(54.3)$ & $96(45.7)$ \\
Want to limit & $7(15.4 \%)$ & $27(51.9 \%)$ & $17(32.7)$ & $51(36.7)$ & $88(63.3)$ \\
Undecided & $7(21.2)$ & $20(60.6)$ & $6(18.2)$ & $33(48.5)$ & $35(51.5)$ \\
\hline \hline
\end{tabular}

Others include: IUD, Injectables, Condom, Implants, Diaphragm, Spermicidal, Sterilization and LAM.

More than half, 219 (54.2\%), of the women in the extended postpartum period were not currently practicing any modern contraceptive at the time of interview. The postpartum women pointed out various reasons for currently not using contraceptives. The major reasons for not currently using contraceptives were feeling of not exposed to the risk of pregnancy due to amenorrhea after birth, 67 (30.9\%), followed by feeling of not exposed to the risk of pregnancy due to breastfeeding, $31(14.3 \%)$, and fear of change in breast milk content as the result of contraceptives, 24 (11.1\%) (Figure1).

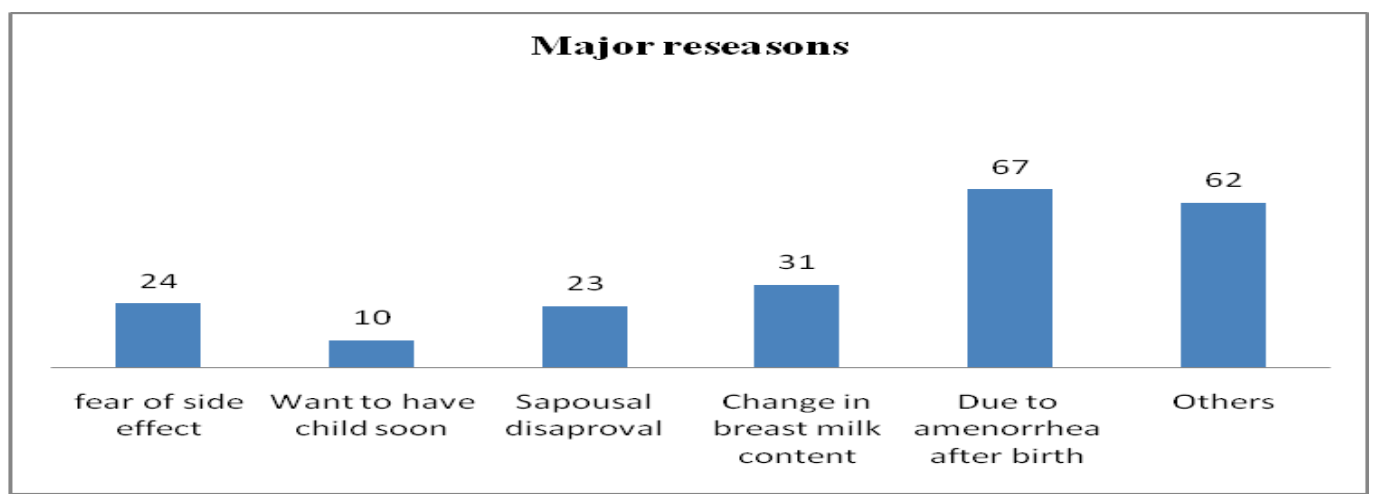

Figure 1: Major reasons for not using modern contraceptives during the extended postpartum period in Gondar town, northwest Ethiopia, April 2015 (Others include: Devotion and departure from their husband, lack of awareness, absence of chosen method)

DOI: http://dx.doi.org/10.4314/ejhs.v28i2.12 
Factors associated with the use of modern contraceptives during the extended postpartum period: On multivariable analysis, factors that were found to be significantly associated with the use of modern contraceptives during the extended postpartum period were menstrual status, duration of postpartum, knowledge on family planning, husband approval and resuming sexual activity.

Postpartum women who started menstruation were about 3.8 times $[\mathrm{AOR}=3.84,95 \% \mathrm{CI}=(2.33$, 6.35)] more likely to use contraceptives in the extended postpartum period as compared to those who were amenorrheic. The likelihood of using contraceptives in the extended postpartum period was 3.2 times higher among postpartum woman who started sexual activity compared with abstainers $[\mathrm{AOR}=3.17,95 \% \mathrm{CI}=(1.80,5.58)]$. The odds of modern contraceptive use increased in later times of postpartum period. Those who were within 2536 and 37-51 weeks of postpartum period were about 2.4 times $[\mathrm{AOR}=2.42,95 \% \mathrm{CI}=(1.25$, 4.68)] and 2.5 times $[\mathrm{AOR}=2.48,95 \% \mathrm{CI}=(1.11$, 5.55)] more likely to use contraceptives respectively than those who were within the first 12 weeks of postpartum period.

Moreover, current use of contraceptive was highly associated with knowledge of at least one FP method. Postpartum women who knew at least one contraceptive method were about 5 times $[\mathrm{AOR}=5.01,95 \% \mathrm{CI}=(2.23,11.24)]$ more likely to use contraceptive than those who did not know at least one contraceptive method. Husband approval of contraceptive use was also found to be one of the predictors of contraceptive use in the extended postpartum period. The probability of postpartum women was 2.1 times higher with woman whose husbands approved for contraceptives usage compared with those whose husbands did not approve contraceptive use $[\mathrm{AOR}=2.10,95 \% \mathrm{CI}=(1.16,3.82)]($ Table 3$)$.

Table 3: Bivariate and Multivariate analysis of factors associated with the use of modern contraceptives during the extended postpartum period, Gondar town, Northwest Ethiopia, April 2015.

\begin{tabular}{|c|c|c|c|c|c|}
\hline \multirow{2}{*}{\multicolumn{2}{|c|}{ Variables }} & \multicolumn{2}{|c|}{ Current Use of FP } & \multirow{2}{*}{ COR (95\%CI) } & \multirow{2}{*}{ AOR $(95 \% C I)$} \\
\hline & & Yes & No & & \\
\hline \multicolumn{6}{|c|}{ Menstrual status } \\
\hline ○ & Menses Started & $114(69.9)$ & $49(30.1)$ & $5.571(3.61,8.60) * *$ & $3.84(2.33,6.35) * *$ \\
\hline o & Amenorrhic & $71(29.9)$ & $170(70.5)$ & 1 & \\
\hline \multicolumn{6}{|c|}{ Weeks of post partum } \\
\hline 0 & $6-12$ & $66(33.7)$ & $130(66.3)$ & 1 & \\
\hline 0 & $13-24$ & $28(41.2)$ & $40(58.8)$ & $1.379(.78,2.43)$ & $.88(.45,1.74)$ \\
\hline$\circ$ & $25-36$ & $56(65.1)$ & $30(34.9)$ & $3.677(2.16,6.28)^{* *}$ & $2.42(1.25,4.68) * *$ \\
\hline & $37-51$ & $35(64.8)$ & $19(35.2)$ & $3.63(1.93,6.83) * *$ & $2.48(1.11,5.55) * *$ \\
\hline \multicolumn{6}{|c|}{ Knowledge on FP } \\
\hline$\circ$ & yes & $173(50.7)$ & $168(49.3)$ & $4.38(2.25,8.50) * *$ & $5.01(2.23,11.24) * *$ \\
\hline o & no & $12(19)$ & $51(81)$ & 1 & \\
\hline \multicolumn{6}{|c|}{ Discussion with husband } \\
\hline ○ & yes & $153(49.5)$ & $156(50.5)$ & $1.93(1.19,3.12)^{* * *}$ & $1.720(.94,3.14)$ \\
\hline ○ & no & $32(33.7)$ & $63(66.3)$ & 1 & \\
\hline \multicolumn{6}{|c|}{ Husband approval } \\
\hline 0 & approve & $156(54.9)$ & $128(45.1)$ & $3.82(2.37,6.17)^{* * *}$ & $2.104(1.16,3.82) * *$ \\
\hline 0 & disapprove & $29(24.2)$ & $91(75.8)$ & 1 & \\
\hline \multicolumn{6}{|c|}{ Sexual activity } \\
\hline o & resumption of sex & $155(59.2)$ & $107(40.8)$ & $5.36(3.34,8.59) * *$ & $3.17(1.80,5.58) * *$ \\
\hline 0 & abstinence & $30(21.3)$ & $111(78.7)$ & 1 & \\
\hline \multicolumn{6}{|c|}{ Previous use of FP } \\
\hline 0 & yes & $143(54.4)$ & $120(45.6)$ & $2.81(1.82,4.34)^{* * *}$ & $1.61(.94,2.76)$ \\
\hline 0 & no & $48(29.8)$ & $99(70.2)$ & 1 & \\
\hline
\end{tabular}

DOI: http://dx.doi.org/10.4314/ejhs.v28i2.12 


\section{DISCUSSION}

Postpartum family planning is the prevention of unplanned pregnancy and closely spaced pregnancies through the first 12 months after childbirth (1) Therefore, the first year after a woman has given birth is an essential period for the uptake of contraceptives to prevent unintended pregnancy (21). This cross sectional study was attempted to investigate the contraceptive practices of women in the first year after delivery when contraceptive behavior is different from other times due to breastfeeding, lactation amenorrhea, abstinence and other determinant factors.

The study revealed that contraceptive the prevalence rate of this study during the extended postpartum period was $45.8 \%$. This is comparable with studies conducted in northern Ethiopia (48\%) (10), Northwest Ethiopia 48.4\% (22), Bahir Dar $48.8 \%$ (20) and Rwanda 50\% (23). However, it is slightly lower than the study carried out in Addis Abeba, Ethiopia (52.5\%) (24) and Kenya (86.3\%) (25). However, this prevalence is higher than the study done in Uganda (28\%) (26), western Ethiopia (28.3\%) (27), in North and South Gondar Zones (22\%) (28), Somali Region, Eastern Ethiopia (12.3\%) (25). These differences might be due to the fact that postpartum women may not realize that they are at risk of pregnancy even if they are breastfeeding. On the other hand, the difference could be the fact that this study was done on women who were in the postpartum period when there was a high motivation to use family planning methods.

The most commonly used contraceptive methods in the current study were injectables $(55.6 \%)$ and pills $(22.2 \%)$. These degrees of preference were in line with studies conducted in Gondar and Northern Ethiopia $(10,22)$. This would be attributed to clients' preferences for a specific method as well as the accessibility and availability of chosen methods.

Women in the postpartum whose duration of postpartum from 6-12 months was more likely to utilize postpartum contraceptive than duration between 6 week and 3 month postpartum. This study is supported by recent cross-sectional studies conducted in Gondar Town, Somalia Region, Eastern Ethiopia (25), and Marrakesh Morocco (29). The reason might be due to the reluctance of women in the early postpartum period to use contraceptives as coital frequency and fertility might be reduced. Besides, family planning providers might defer to give contraceptives immediately after birth. The other possible justification could be due to the fact that the majority of women were abstainers in the first three months of postpartum period.

Resuming sexual activity was significantly associated with postpartum modern contraceptive use. Similar findings were reported in studies conducted in Malawi (30), Thailand (31) and Northern Ethiopia (10). The explanation for this may be the fact that when postpartum women resume sexual activity and they perceive themselves to be at risk for unintended pregnancy, which motivates them to adopt contraceptive methods.

Women whose menses returned after birth were found to be significantly associated with the use of modern contraceptives in the postpartum period. This finding is supported by reports from Nairobi, Kenya (32), India (33) Gondar Town (22) and North and South Gondar zones, Northwest Ethiopia (28).This is because women may be aware of their fertility returning when menses resumes. Moreover, ammenhorric women would underestimate the risk of pregnancy by assuming that amenorrhea could guarantee protection against pregnancy regardless of the time of postpartum period.

Husband approval of contraception was significantly affecting women's use of contraceptive method during the extended postpartum period in the present study. This is in line with a study done in Nigeria (34) and in Ethiopia (35). This can be explained by the fact that any factor that influences the partner's attitude towards contraceptives would also affect women's use of postpartum contraceptives either negatively or positively.

Postpartum women who had knowledge about modern contraceptives were more likely to utilize postpartum contraceptive than their counterparts. The findings showed that the use of

DOI: http://dx.doi.org/10.4314/ejhs.v28i2.12 
a modern method of contraception during the postpartum period is significantly associated with current knowledge on modern contraceptive. This is in line with previous reports from Kebri Beyah Town, Eastern Ethiopia (37) and Jimma Town, Ethiopia (35). This is explained by the fact that the level of awareness determines the use of modern contraceptives. However, there are studies that showed knowledge is not significantly associated with the use of modern contraceptive in Malawi (30) and two studies in Ethiopia $(10,36)$. This suggests that knowledge of contraceptive methods has not yet been translated into contraceptive practice. Women stated that their reasons for not using modern contraceptives during the postpartum period were menses not resuming/lower perceived risk for pregnancy, fear of side effects, spousal disapproval and fear of change in breast milk content as the result of contraceptives. Similar reasons have been documented in studies conducted in Malawi (30), Gondar (22) and North Ethiopia (10).

In conclusion, this study showed that the prevalence of postpartum contraceptive utilization was in the study area $(45.8 \%)$. This study demonstrated that the majority of women in the extended postpartum period were using short term hormonal family planning methods (Injectables and Pills) than the long term methods despite the intention of the majority to limit their family size or space next pregnancy. Utilization of contraceptive in the postpartum period is influenced by factors such as menses returning after birth, resumption of sex, 6-12 months of postpartum period, husband approval of contraceptive and current on knowledge contraceptive use. The reasons for non-use of contraceptives were menses not resuming, fear of side effects, spousal disapproval and fear of change in breast milk content.

Therefore, health professionals should work on making awareness of the women and counseling of their husbands about the use of postpartum contraception, when fertility returned and risky timing for becoming pregnant.

Postpartum family planning should be integrated with other maternal health services like
ANC and postnatal care. In addition, policy makers and program managers need to focus on improving male involvement in maternal health care issues especially on family planning service. The study does not include data on the qualitative information of study participants.

\section{ACKNOWLEDGEMENTS}

We would like to thank the University of Gondar for all the support given to us to conduct this study. We also thank all the study participants for their willingness to give us all the necessary information.

\section{REFERENCES}

1. Organization WH. Programming strategies for postpartum family planning. 2013.

2. Stephenson P, MacDonald P. Family planning for postpartum women: seizing a missed opportunity. 2005.

3. Organization WH. WHO recommendations on postnatal care of the mother and newborn: World Health Organization; 2014.

4. Ross JA, Winfrey WL. Unmet need for contraception in the developing world and the former Soviet Union: an updated estimate. International family planning perspectives. 2002;138-43.

5. Audu B, Yahya S, Bassi A. Knowledge, attitude and practice of natural family planning methods in a population with poor utilisation of modern contraceptives. Journal of obstetrics and gynaecology. 2006;26(6):555-60.

6. Organization WH. Report of a WHO technical consultation on birth spacing. 2005. Hallado en: http://whqlibdoc who int/hq/2007/WHO_RHR_07 1_ eng pdf Acceso el. 2014;8.

7. DaVanzo J, Hale L, Razzaque A, Rahman M. Effects of interpregnancy interval and outcome of the preceding pregnancy on pregnancy outcomes in Matlab, Bangladesh. BJOG: An International Journal of Obstetrics \& Gynaecology. 2007;114(9):1079-87. 
8. Conde-Agudelo A, Belizán JM. Maternal morbidity and mortality associated with interpregnancy interval: cross sectional study. Bmj. 2000;321(7271):1255-9.

9. Tawfeek RS, Khaleel HA, Mustafa ZM. ISpacing Effects on Maternal-Child Health. A Hospital Based Study at Tikrit Teaching Hospital. Tikrit Medical Journal. 2011;17(2).

10. Abraha TH, Teferra AS, Gelagay AA. Postpartum modern contraceptive use in northern Ethiopia: prevalence and associated factors. Epidemiology and health. 2017;39: e2017012 doi: 10.4178/epih.e2017019r

11. 1Pörtner CC, Beegle K, Christiaensen L. Family planning and fertility: Estimating program effects using cross-sectional data. 2011.

12. Shepherd A. Conclusion and policy implications. Chronic poverty: Concepts, causes and policy. 2013;270.

13. Shonkoff JP, Richter L, van der Gaag J, Bhutta ZA. An integrated scientific framework for child survival and early childhood development. Pediatrics. 2012;129(2):e460-e72.

14. Ross JA, Winfrey WL. Contraceptive use, intention to use and unmet need during the extended postpartum period. International family planning perspectives. 2001 Mar 1:207.

15. Vernon R. Meeting the family planning needs of postpartum women. Studies in family planning. 2009;40(3):235-45.

16. Shankar A, Bartlett L, Fauveau V, Islam M, Terreri N, Group CtMH. Delivery of MDG 5 by active management with data. The Lancet. 2008;371(9620):1223-4.

17. Organization WH. The World Health Report 2005: Make every mother and child count: World Health Organization; 2005.

18. Cleland J, Bernstein S, Ezeh A, Faundes A, Glasier A, Innis J. Family planning: the unfinished agenda. The Lancet. 2006;368(9549):1810-27.

19. Hernandez LE, Sappenfield WM, Goodman D, Pooler J. Is effective contraceptive use conceived prenatally in Florida? The association between prenatal contraceptive counseling and postpartum contraceptive use. Maternal and child health journal. 2012;16(2):423-9.

20. Shegawe M. Assessment of the contraceptive needs and practice of women in the extended postpartum Period In Bahir Dar Ethiopia. 2008.(Unpublished thesis)

21. Borda MR, Winfrey W, McKaig C. Return to sexual activity and modern family planning use in the extended postpartum period: an analysis of findings from seventeen countries. African journal of reproductive health. 2010;14(4): 72-9.

22. 2Abera Y, Mengesha ZB, Tessema GA. Postpartum contraceptive use in Gondar town, Northwest Ethiopia: a community based cross-sectional study. BMC women's health. 2015;15(1):19.

23. Brunie A, Tolley EE, Ngabo F, Wesson J, Chen M. Getting to $70 \%$ : Barriers to modern contraceptive use for women in Rwanda. International Journal of Gynecology \& Obstetrics. 2013; Nov 1;123(S1)

24. Demographic E. Health Survey 2005. Addis Ababa, Ethiopia and Calverton, Maryland, USA: Central Statistical Agency and ORC Macro. 2011.

25. Jalang'o R, Thuita F, Barasa SO, Njoroge P. Determinants of contraceptive use among postpartum women in a county hospital in rural Kenya. BMC public health. 2017;17(1):604.

26. Rutaremwa G, Kabagenyi A, Wandera SO, Jhamba T, Akiror E, Nviiri HL. Predictors of modern contraceptive use during the postpartum period among women in Uganda: a population-based cross sectional study. BMC public health. 2015;15(1):262.

27. Kenate W, Amenu D. Assessment of contraceptive needs and practices of women during the extended postpartum period in Kiramu Woreda, Western Ethiopia. International Journal of Advanced Biological and Biomedical Research. 2015;3(4):341-50.

28. Alene GD, Worku A. Estimation of the total fertility rates and proximate determinants of fertility in North and South Gondar zones, Northwest Ethiopia: An application of the 
Bongaarts' model. Ethiopian Journal of Health Development. 2009;23(1):

29. Moultrie TA, Timaeus IM, editors. Stopping, spacing and postponing-Evidence of a uniquely African pattern of fertility decline. XXVI International Population Conference of the International Union for the Scientific Study of Population, Marrakesh, Morocco Retrieved from princeton edu/download aspx; 2009.

30. Bwazi C, Maluwa A, Chimwaza A, Pindani M. Utilization of postpartum family planning services between six and twelve months of delivery at Ntchisi District Hospital, Malawi. Health. 2014;6(14):1724.

31. Zerai A, Tsui AO. The relationship between prenatal care and subsequent modern contraceptive use in Bolivia, Egypt and Thailand. African journal of reproductive health. 2001;5(2):68-82.

32. Ndugwa RP, Cleland J, Madise NJ, Fotso J-C, Zulu EM. Menstrual pattern, sexual behaviors, and contraceptive use among postpartum women in Nairobi urban slums. Journal of Urban Health. 2011;88(2):341-55.

33. Sarvamangala K, Taranum A. Menstrual pattern, sexual behavior and contraceptive use among postpartum women in a tertiary care hospital in Davangere. Medica Innovatica. 2013; 2(2):175.

34. Adegbola O, Okunowo A. Intended postpartum contraceptive use among pregnant and puerperal women at a university teaching hospital. Archives of gynecology and obstetrics. 2009;280(6):987-92.

35. Haile A, Enqueselassie F. Influence of women's autonomy on couple's contraception use in Jimma town, Ethiopia. Ethiopian Journal of Health Development. 2006;20(3):

36. CSA-Ethiopia I. International: Ethiopia Demographic and Health Survey 2011. Central Statistical Agency of Ethiopia and ICF International Addis Ababa, Ethiopia and Calverton, Maryland, USA. 2012.

37. Nigussie AT, Girma D, Tura G .Postpartum family planning utilization and associated factors among women who gave birth in the past 12 months, Kebri Beyah town, Somali region,eastern Ethiopia. J Women's Health Care. 2016; 5: 340 